\title{
OS SENTIDOS DA INTEGRAÇÃO NO PROEJA-FIC/FUNDAMENTAL: LIMITES E ALCANCES DE UM CURSO DESENVOLVIDO EM ESPAÇO PRISIONAL
}

\author{
A. I. P. DINIZ* e D. H. MOURA \\ Instituto Federal de Educação, Ciência e Tecnologia do Rio Grande de Norte \\ ana.diniz@ifrn.edu.br
}

Artigo submetido em julho/2015 e aceito em julho/2015

DOI: $10.15628 /$ holos.2015.3196

\section{RESUMO}

Este artigo é um recorte temático da nossa Dissertação de Mestrado em Educação. Tem como objetivo analisar os sentidos da integração de um curso FIC vinculado ao PROEJA FIC/FUNDAMENTAL, ofertado pelo IFRN campus Mossoró em espaço prisional, considerando a abrangência desse Programa, seus limites e alcances. As técnicas de pesquisa desenvolvidas foram a análise documental, a aplicação de questionário, a realização de grupo focal e a observação in loco, adotando-se por dimensões de análises a integração curricular, elevação de escolaridade e formação humana integral. Apesar de o PROEJA abranger a integração da educação profissional à educação básica, neste estudo, a análise concentra-se na integração entre cursos FIC e EJA nos anos finais do ensino fundamental. $\mathrm{O}$ artigo evidencia aspectos relevantes acerca dos pressupostos imbricados nas possibilidades de integração entre EJA, Cursos FIC ou Qualificação Profissional e educação em prisões e na efetivação do PROEJA FIC/FUNDAMENTAL como parte de uma política social de inclusão emancipatória, conforme declaração oficial.

PALAVRAS-CHAVE: PROEJA, EJA, Educação em Prisões, Integração, Formação Humana

\section{THE WAYS OF INTEGRATION IN PROEJA-FIC/FUNDAMENTAL: LIMITS AND REACHES OF A LECTURA DEVELOPED IN PRISON SPACE}

\begin{abstract}
This article presents a thematic snippet of a broader research, developed on the master's degree in Education, that aimed to analyze how works a FIC lecture bound to PROEJA, in the integrated with basic education form on EJA genre, offered in prison space by IFRN campus Mossoró. The objective is to analyze the perceptions and impressions of people involved in PROEJA FIC/FUNDAMENTAL, over the coverage of this program, its limits and reaches. The research technics developed were the document analysis, questionnaire application, focus group realization and the in loco observation, adopting for analysis dimensions the curriculum
\end{abstract}

integration, scholarity elevation and full human formation. Although PROEJA covers the integration from professional to basic education, in this study, the analysis focus on the integration between FIC and EJA on the final years of basic education. The article shows relevant aspects over interwoven assumptions on the possibilities of integration between EJA, FIC lectures or professional qualification and education in prisons and in the effectuation of PROEJA FIC/FUNDAMENTAL as a part of a social policy of emancipatory inclusion, as official statement.

KEYWORDS: petroleum, environmental risks, drilling rig, the risk maps. 


\section{INTRODUÇÃO}

O Programa Nacional de Integração da Educação Profissional com a Educação Básica na Modalidade de Educação de Jovens e Adultos (PROEJA) associa formação geral à educação profissional, ao articular a modalidade EJA (fundamental e médio) a cursos técnicos ou cursos de qualificação profissional (FIC). Envolve cursos em formas diferenciadas e ofertados na modalidade presencial, semipresencial e a distância, com propostas educativas para comunidades das zonas rural e urbana, podendo, ainda, desenvolver-se por meio de projetos voltados ao atendimento às seguintes minorias: PROEJA INDÍGENA (para a população indígena); PROEJA PESCA (para a população ribeirinha); PROEJA QULOMBOLA (para a população de comunidades quilombolas); e PROEJA PRISIONAL (para as pessoas jovens e adultas em situação de restrição e privação de liberdade).

Apesar de o PROEJA abranger a integração da educação profissional à educação básica, neste estudo, a análise concentra-se na integração entre cursos FIC e EJA nos anos finais do ensino fundamental, ou seja, o PROEJA FIC/FUNDAMENTAL. Nesse formato associa formação inicial e continuada ou qualificação profissional - cursos FIC ao ensino fundamental na modalidade EJA, seja nas formas integrada ou concomitante, unindo três princípios basilares: elevação de escolaridade, formação humana integral e integração curricular. E no caso do objeto desta investigação, o "Curso FIC de Auxiliar Técnico em Gestão e Qualidade em Serviços, na forma integrada ao ensino fundamental, na modalidade EJA", desenvolvido em espaço prisional pelo Instituto Federal do Rio Grande do Norte - campus Mossoró, o Programa se articula, também, à educação em prisões. Como ponto de partida, as três questões a seguir norteiam esse debate. São elas: a) qual o cenário das políticas públicas educacionais de Estado para o sistema prisional brasileiro?; b) quais as percepções dos estudantes, docentes e gestores do curso investigado sobre o PROEJA FIC/FUNDAMENTAL?; e c) quais as impressões desses mesmos sujeitos a respeito do curso cujo fundamento é associar, ao mesmo tempo, EJA e qualificação profissional-FIC?

Por meio de pesquisa bibliográfica de cunho exploratório, de revisão de literatura, análise documental e pesquisa de campo, com a utilização de técnicas da pesquisa qualitativa, nesse artigo objetiva-se analisar os sentidos da integração de um curso FIC vinculado ao PROEJA FIC/FUNDAMENTAL, ofertado pelo IFRN campus Mossoró em espaço prisional, considerando a abrangência desse Programa, seus limites e alcances. Para a recolha dos dados utilizou-se o questionário junto aos estudantes, realizou-se o grupo focal junto a docentes/gestores do curso e a observação in loco, sendo seis estudantes, doze docentes e seis gestores das três instituições parceiras, envolvidas nos processos de gestão pedagógica e administrativa do curso investigado. Entende-se ser relevante apreender as impressões dos sujeitos de pesquisa, na busca de identificar os significados do curso ofertado e analisar os sentidos atribuídos, por eles, a um Programa que se pretende parte de uma política social de inclusão emancipatória e em vista da integração anunciada, oficialmente (BRASIL, 2007).

No tratamento dos dados foram feitas análises das falas mediadas pela triangulação de sujeitos, identificados no texto, como: estudantes (E1, E2, E3, E4, E5 e E6); docentes (D1, D2, D3, D4, D5, D6, D7, D8, D9, D10, D11 e D12), e gestores (G1, G2, G3, G4, G5 e G6). Articula-se teoria à empiria, na compreensão de que a teoria se posiciona como um conjunto coerente de proposições que inter-relaciona concepções, princípios e definições "para dar organização lógica à 
interpretação da realidade empírica" Minayo (2010, p. 175). Já a empiria se traduz na ideia de que "os mecanismos de desigualdade e de dissimetria na sociedade são muito mais amplos e problemáticos e estão presentes em todas as relações" (MINAYO, 2010, p. 175). Buscou-se dialogar com autores, como Freire (1994, 2005), Marx (1982), Frigotto; Ciavatta; Ramos (2005) e Foucault (2001), dentre outros teóricos que contribuem para o debate em foco.

A organização do texto, além da introdução, em que situa o leitor em relação ao objetivo deste estudo, compreende mais quatro partes. Na primeira parte discutem-se os fundamentos e as bases do PROEJA FIC/FUNDAMENTAL entrecruzando o declarado no discurso oficial com os pontos de vista dos teóricos que balizam esses fundamentos. Na segunda parte reflete-se sobre os sentidos da integração anunciada no PROEJA FIC/FUNDAMENTAL, entrelaçando os contextos nacional e local, os pontos de vista dos sujeitos de pesquisa, as declarações oficiais e as teorias que dão sustentáculo à integração entre EJA, qualificação profissional - cursos FIC e educação em prisões. Na terceira parte as especificidades do curso investigado e os meandros envolvido nesse universo, relacionando bases legais, teoria e empiria, de modo a analisar dificuldades, fragilidades e acertos evidenciados na gestão administrativo-pedagógica do curso investigado. Por último, a parte quatro retrata, a título da provisoriedade das conclusões, os sentidos e significados da investigação acerca dos limites e alcances que se desvelam em vista de propostas mais condizentes com as reais necessidades de jovens e adultos em situação de restrição e de privação de liberdade.

\section{INTEGRAÇÃO ENTRE EJA E QUALIFICAÇÃO PROFISSIONAL-CURSOS FIC: BASES E FUNDAMENTOS DO PROEJA FIC/FUNDAMENTAL}

Em meados dos anos 2000 evidencia-se, no Brasil, a prevalência de iniciativas governamentais destinadas a pessoas jovens e adultas com baixa ou nenhuma escolaridade desconectadas da elevação da escolaridade e focalizadas, essencialmente, na preparação para o trabalho imediato. Implica dizer que perduram, historicamente, ações educacionais de qualificação e formação profissional cujas intenções alinham-se muito mais ao setor produtivo do que ao aspecto social, negligenciando-se, por vezes, os alcances sociais de um projeto que tenha a educação, como direito, e a formação humana integral, como primazia.

Dentre as poucas iniciativas federais implementadas que acenaram para as possibilidades de elevação da escolaridade, de modo a promover formação integral (humana), unindo educação básica e educação profissional ao mesmo tempo, está o Programa Nacional de Integração da Educação Profissional com a Educação Básica na Modalidade de Educação de Jovens e Adultos PROEJA, criado no ano de $2005^{1}$ cujo redimensionamento, em 2006, originou o PROEJA FIC/FUNDAMENTAL.

Constituem-se bases os marcos regulatórios desse Programa, como o Decreto 5.840, de 13 de julho de 2006, e o Documento Base do PROEJA FIC/FUNDAMENTAL (BRASIL, 2007a), dentre outras leis, decretos e pareceres que regem, separadamente, cada uma das ofertas envolvidas. $O$ referido Documento-Base, de caráter orientador e não prescritivo, traça as diretrizes de implementação e apresenta a concepção, os princípios norteadores, os objetivos e as finalidades do PROEJA FIC/FUNDAMENTAL. No tocante aos fundamentos declarados, destacam-se os

\footnotetext{
${ }^{1}$ Registra-se que a primeira proposição oficial do PROEJA veio por meio da Portaria SETEC/MEC no 2.080 , de 13 de junho de 2005 , que estabelecia as diretrizes para a criação do Programa em algumas instituições do País. Foi posteriormente instituído por meio do Decreto no 5.478, de 24 de junho de 2005.
} 
seguintes princípios: a concepção de trabalho, a elevação de escolaridade, a integração curricular e a formação humana integral.

A concepção de trabalho declarada como primeiro fundamento do Programa expressa a ideia de trabalho como princípio educativo, explicitada como atividade vital que torna possível a existência e a reprodução da vida e da sobrevivência humana em sociedade. No arranjo do que se desenha, a concepção de trabalho anunciada tem como um dos pressupostos político-pedagógicos a preparação para o trabalho que visa a "[...]valorizar as dimensões filosófica, estética, política e ética, ultrapassando os limites estreitos do utilitarismo da Educação Profissional, superando a pedagogia taylorista/fordista que norteou por longos anos a formação dos trabalhadores" (BRASIL, 2007b, p. 32-33).

A perspectiva anunciada distancia-se, teoricamente, da noção de trabalho produtivo, de caráter exploratório, e se aproxima do trabalho como substância humana, de caráter educativo. Esse debate reforça, sobremaneira, a estreita relação que existe entre educação profissional e trabalho, guiada pela noção de trabalho como princípio educativo (CIAVATTA, 2005). Assim, as aproximações entre qualificação profissional e trabalho cindidas nesse fundamento devem convergir para os atributos da condição humana nos processos do mundo do trabalho, na tentativa de perseguir a uma concepção que venha de encontro à manutenção da separação entre o pensar e o fazer (RAMOS, 2007). Nota-se que é preciso manter-se vigilante e atuante na luta que se contrapõe à reprodução de modelos hegemônicos, como forma de reverter a massiva manobra dos meios de produção capitalista no combate à submissão dos princípios humanos e sociais aos do capital, de maneira que se possa inverter a lógica da força de trabalho como mercadoria para a noção primordial do trabalho como atividade essencialmente humana e inalienável, conforme declara Marx (1982).

Nesse alcance, um dos caminhos-meio é o da formação respaldada no trabalho como princípio educativo, fundada nas perspectivas ontológica, humana, cidadã e emancipatória do trabalho (RAMOS, 2005). Esta é condição sine qua non para contrapor ao ideário neoliberal cujos princípios ainda orientam boa parte das propostas educacionais vigentes.

O segundo fundamento declarado no Programa é o da elevação de escolaridade. Essa noção remete-se, essencialmente, a um cenário social composto por um grande contingente de pessoas que teve subtraído um direito de não poder dar prosseguimento aos estudos. Convém esclarecer que a primazia da qualificação profissional desvinculada da escolarização, além de desconsiderar um princípio constitucional, distancia-se, acima de tudo, da possibilidade de se obter uma

[...] qualificação para o exercício do trabalho em condições ideais, ou seja, de modo que o trabalhador, ao realizar a sua atividade na oficina, na loja, no campo, na fábrica reconheça que as técnicas por ele desenvolvidas decorrem de teorias, de conhecimentos abstratos, de culturas gerais, construídas ao longo dos anos nas práticas sociais (ROCHA, 2011, p. 237).

Apesar de se considerar que elevar a escolarização de sujeitos sem a necessária articulação com a formação profissional é possível, o contrário não é recomendável. Ou seja, do ponto de vista social e político, quando um projeto ou programa educativo prescinde do pressuposto da escolarização e volta-se, exclusivamente, à qualificação profissional, suplanta a elevação da 
escolaridade. E em uma proposta no qual a escolarização é secundarizada, reduz-se, sobremaneira, a função social da educação.

O desenho curricular expresso no Documento constitui o terceiro fundamento declarado para o PROEJA FIC/FUNDAMENTAL: a integração curricular. A orientação é que o currículo deva

[...] ser construído a partir do conjunto das relações sociais estabelecidas pelos trabalhadores, setor produtivo e a sociedade. Nessa construção, precisa-se levar em consideração os conhecimentos, as experiências dos sujeitos bem como suas diversidades. Dessa forma, o currículo precisa expressar claramente essas relações nos seus princípios, programas e metodologias e não constituir-se apenas como uma série ordenada de conteúdos (BRASIL, 2007b, p. 28).

A noção defendida busca romper com a ideia de currículo, exclusivamente, como estratégia metodológica. Pressupõe uma integração de natureza epistemológica, de conteúdo, de metodologias e de práticas educativas. Implica na "integração teoria-prática, entre o saber e o saber-fazer. [...] um currículo traduzido em termos de integração entre uma formação humana mais geral, uma formação para o ensino médio e para a formação profissional" (BRASIL, 2007a, p.41).

Na formalização do Programa o que define o currículo é a "integração proposta entre o ensino fundamental e a formação inicial para o trabalho, fazendo-se necessário o conhecimento das especificidades desses campos, incorporando-os na construção do currículo integrado" (BRASIL, 2007b, p. 27). Para Machado (2010, p.81) adotar os pressupostos da integração curricular como centralidade em um projeto como esse, sugere-se um processo "dinâmico, aberto e formativo e sua estratégia de concepção e implementação precisa ser participativa, construída, tendo em vista assegurar sua eficiência no saber encontrar os meios de atingir os objetivos da aprendizagem".

Nessa mesma linha de raciocínio, a ideia de integrar defendida por Ciavatta (2005) baliza a compreensão de currículo explicitada no Documento Base do programa. Integrar é

[...] tornar íntegro, tornar inteiro, o quê? A palavra toma o sentido moral em alguns usos correntes. Mas não é disto que se trata aqui. Remetemos o termo ao seu sentido de completude, de compreensão das partes no seu todo ou da unidade no diverso, de tratar a educação como uma totalidade social, isto é, nas múltiplas mediações históricas que concretizam os processos educativos [...]. Significa que buscamos enfocar o trabalho como princípio educativo, no sentido de superar a dicotomia trabalho manual/trabalho intelectual, de incorporar a dimensão intelectual ao trabalho produtivo, de formar trabalhadores capazes de atuar como dirigentes e cidadãos (CIAVATTA, 2005, p. 84).

Sem dúvida, isso constitui uma tarefa desafiadora. No conjunto dos desafios postos nesse alcance está, sobretudo, a formação de profissionais (docentes, técnicos e gestores) para atuar no Programa, de modo a compreender as nuances, os sentidos, os significados e as inter-relações necessárias a uma prática pedagógica fundada na concepção de integração curricular. Essa é, portanto, a noção de currículo que se desenha das intenções declaradas.

Também é princípio fundante, declarado na formulação do Programa, a formação integral [humana]. Segundo o Documento Base, 
[...] o que se aspira é uma formação que permita a mudança de perspectiva de vida por parte do aluno; a compreensão das relações que se estabelecem no mundo do qual ele faz parte; a ampliação de sua leitura de mundo e a participação efetiva nos processos sociais. Enfim, uma formação plena. Para tanto, o caminho escolhido é o da formação profissional aliada à escolarização, tendo como princípio norteador a formação integral (BRASIL, 2007b, p. 5).

A formação integral está balizada pela compreensão de completude (CIAVATTA, 2005). Quando se trata de educação integral, a ideia de formação implícita remete a articular currículos, disciplinas, conhecimentos, o que se aplica muito bem ao contexto do Programa, uma vez que se associam currículos e conhecimentos da formação geral com os da formação profissional. Quando se trata da formação integral do sujeito, é uma noção que guarda similaridade com a omnilateralidade, ou seja, vislumbra a formação humana nas dimensões ontológicas e históricas do ser humano.

Muito embora se anuncie, oficialmente, a formação integral [humana] como princípio, isso somente será possível quando da assunção pela integração curricular e pelo currículo integrado, que se traduzem na articulação de um currículo que contempla todas as formas de conhecimento produzidas pela atividade humana em sua completude (CIAVATTA; FRIGOTTO; RAMOS, 2005).

Essas são, em tese, as bases e os fundamentos declarados no discurso oficial que concebe e sedimenta o desenvolvimento desse Programa em todas as suas possibilidades de ofertas de cursos.

\section{SENTIDOS DA INTEGRAÇÃO ANUNCIADA NO PROEJA FIC/FUNDAMENTAL: ENTRELAÇANDO CONTEXTOS, TEORIAS, PONTOS DE VISTA E MARCO LEGAL}

Do ponto de vista de suas finalidades, esse Programa foi concebido com o propósito de contribuir para a superação de lacunas deixadas pela inconclusão da educação básica de uma parcela da população brasileira, tencionando elevar a escolaridade por meio da EJA articulada à qualificação profissional - cursos FIC, a milhões de jovens e adultos, trabalhadores ou não, que deixaram de concluir o ensino fundamental (BRASIL, 2007b). As falas que seguem traduzem a percepção de três dos sujeitos entrevistados a respeito dessas finalidades anunciadas.

[...] quando se pensou num projeto de unir a educação e a questão profissional, essa parte da filosofia eu achei muito interessante, porque no caso da pessoa adulta, ele desperta muito pra questão profissional. [...] Então são duas coisas que vão caminhar juntas e talvez num outro momento, se ele fosse só partir para estudar aquele ensino regular, ele não ia ter chance de se qualificar profissionalmente. Então eu achei a ideia muito mais rica $(G 1,2013)$.

É, eu acho que contribui [o PROEJA FIC/FUNDAMENTAL] para diminuir a evasão, em função de que reúne dois interesses. [...] quando o estudante faz apenas a EJA, a evasão é elevada. E quando você tem aquela formação profissional junta se torna um fator de motivação a mais (D1, 2013).

[...] Então eu considero a filosofia do projeto muito, muito importante. E muito de acordo com o que o preso precisa, que é formação geral mais o curso profissionalizante, que a maioria chega pra gente sem nenhuma profissão, sem 
nenhuma profissão. [...] Então o curso, além de dar a formação geral, já dá ali uma formação profissional. Acho que veio calhar exatamente com o perfil necessário deles $(G 3,2013)$.

Na percepção desses sujeitos, a intenção do Programa de prevê escolaridade para pessoas jovens e adultas que estão fora da escola, permitindo que essas pessoas façam ensino fundamental-EJA associado a uma qualificação profissional-cursos FIC, se confirma como uma proposta acertada. Configura-se, aqui, a defesa pela elevação da escolaridade, coadunando-se com um dos fundamentos do PROEJA FIC/FUNDAMENTAL.

Ressalta-se que, para D1, unir educação básica e educação profissional concomitantemente, além de contribuir para minimizar a histórica evasão escolar na EJA, pode motivar o estudante jovem e adulto a concluir seus estudos, uma vez que "a pessoa adulta estaria tendo essa educação geral, mas também uma formação que atenda uma necessidade de formação profissional". Tem como pressuposto um currículo pensado de forma integrada desde a concepção à metodologia proposta.

Os estudantes também se posicionaram sobre o formato do Programa, mostrando como eles percebem a articulação sugerida, conforme exposto nas falas a seguir.

Fazer os dois ao mesmo tempo é mais positivo pois aumentam as chances de empregos futuros uma vez que já saímos qualificados profissionalmente (E2, 2013).

Fazer o ensino fundamental e o curso é melhor para o preso, pois ele é preparado para ter uma profissão $(E 4,2013)$.

Na minha opinião é bom fazer os dois ao mesmo tempo, por quê traz bons resultados para a nossa vida $(E 5,2013)$.

Apesar de afirmarem estar de acordo com as finalidades e o objetivo que respaldam o PROEJA FIC/FUNDAMENTAL, que é o de articular as duas formações ao mesmo tempo, E2 e E5 expõem seus argumentos dando relevância, apenas, aos benefícios futuros da qualificação profissional. Ambos silenciam quanto à relevância da intenção global dessa formação, que visa abranger as demais dimensões da vida humana, além de “... preparar para ter uma profissão", como afirma E4.

Embora de forma implícita, E5 faz referência ao Programa como algo que terá implicações na vida da pessoa: "fazer os dois ao mesmo tempo traz bons resultados para a nossa vida". Essa integração ganha sentido "ao propiciar aos sujeitos o acesso aos conhecimentos e à cultura construídos pela humanidade, que propicie a realização de escolhas e a construção de caminhos para a produção da vida" (RAMOS, 2007, p. 3). Nesse alcance, uma formação não se sobrepuja a outra, ambas concorrem para o mesmo ideal: o da formação humana integral.

Outro fator extraído da fala a seguir foi identificado nas intenções do PROEJA FIC/FUNDAMENTAL: o do direito. "[...] É o direito do cidadão ao saber, à educação e a receber ensino. E é uma oportunidade que se tá dando aos cidadãos de receber e até interagir com esses conhecimentos, porque a gente não só vai levar conhecimento. [...] a lei está aí para ser cumprida, mas que não seja só como a lei, mas um direito à humanização que não se deve ser negado como pessoa, como sujeito da sua própria história (D2, 2013). 
Da afirmação acima, pelos menos dois aspectos problematizam esse debate. Para D2, o PROEJA FIC/FUNDAMENTAL agrega dois direitos do cidadão: ao saberlà educação e à humanização. Conceber o Programa sob o prisma desses dois direitos implica reconhecer que, historicamente, esses atributos foram negados. A prova disso é a trajetória da EJA no Brasil. Como política de Estado ainda muito fragilizada, a modalidade EJA é fruto de projetos em disputa, de lutas, de movimentos e de algumas poucas conquistas que não se deram por dádiva, pela livre vontade ou pela 'bondade' de alguns governantes. Talvez pelas razões históricas de negação de direitos é que D2 concebe o Programa afirmando, enfaticamente, se tratar de um direito "que não pode ser negado".

Do conjunto das falas analisadas, em consonância com os referenciais teóricos apresentados, é coerente afirmar que, na percepção dos sujeitos, a associação entre EJA e qualificação profissional-cursos FIC, anunciada nas intenções do PROEJA FIC/FUNDAMENTAL, sob as bases e os fundamentos que lhes dão sustentáculo, é uma filosofia acertada para o formato de formação ao qual propõe.

Em sendo assim, o PROEJA FIC/FUNDAMENTAL pode ser posicionado na contramão de finalidades imediatas e mercadológicas por anunciar a elevação da escolaridade integrando EJA e qualificação profissional-Cursos FIC como prerrogativa, desde que vise incluir "[...] formação geral, e educação profissional, técnica ou tecnológica e rompa com a 'cultura dos mínimos', a escolaridade de baixa qualidade e infantilizada, a subalternidade da divisão social do trabalho e o dualismo educacional" (TIRIBA; CIAVATTA, 2011, p. 48).

Por isso, urge coadunar propostas que propiciem ao sujeito compreender as inter-relações de seu entorno, de forma ativa, ética criativa e crítica, a fim de possibilitá-lo transitar nas mais diversas instâncias da sociedade. Somente assim será possível "cumprir, simultaneamente, a finalidade de garantir, aos estudantes, a base unitária da formação geral e a preparação para o exercício de profissões técnicas" sem que haja prejuízos para os sujeitos sociais (RAMOS, 2010, p. 52).

A relevância social dessa articulação é incontestável, uma vez que atende a um significativo contingente de "cidadãos que foram cerceados do direito de concluir a educação básica e de ter acesso a uma formação profissional de qualidade" (BRASIL, 2007a, p. 11). Desse modo, deve ser percebida como modalidade de ensino universal e, portanto, um direito objetivo de cidadania e que extrapole o papel de "política compensatória coadjuvante no combate às situações de extrema pobreza", segundo esclarecem Haddad e Di Pierro (2000, p. 27).

Do conjunto das apreensões feitas acerca dos sentidos e dos significados do Programa, infere-se que o PROEJA FIC/FUNDAMENTAL se inscreve no campo das medidas governamentais capazes de possibilitar e conferir maior significado social, visto que poderá incidir diretamente na melhoria da qualificação profissional quando associada à elevação do nível de escolaridade dos sujeitos aos quais se destina. Entretanto, mesmo estando amparado por força de decreto e embora as recomendações declaradas e as diretrizes para o desenvolvimento dos cursos estejam condizentes, o que está anunciado não é garantia para que a formação requerida no âmbito desse Programa aconteça a contento. Mais notadamente quando articulado à educação em prisões. 


\subsection{ARTICULAÇÃO ENTRE PROEJA FIC/FUNDAMENTAL E EDUCAÇÃO EM PRISÕES: APROXIMAÇÕES E DESAFIOS}

Para compreender a importância do PROEJA FIC/FUNDAMENTAL associado à educação em prisões, faz-se necessário questionar: qual o cenário atual das políticas públicas educacionais de Estado para o sistema prisional brasileiro? Esse debate evoca os significados da educação em espaço escolar não-formal prisão, a partir da relação forjada entre prisão (FOUCAULT, 2001) e humanização (FREIRE, 1994, 2005). Interessa, também, afirmar que os estudos e publicações de pesquisadores, como Onofre (2007; 2011), Bueno (2007), Penna (2011), Julião (2011), Scarfó; Breglia; Frejtman (2011), dentre outros, foram determinantes para tanto para abranger o contexto brasileiro que envolve a educação em prisões no Brasil como para compreender as concepções basilares desse universo e a relevância social de existirem ações educativas em espaços prisionais.

Pensar e planejar ações estatais para a educação em prisões em sua conjuntura macro, mediatizada cultural, humana, histórica, social, ideológica e politicamente pelas contraditórias relações que caracterizam a modernidade, requer guiar-se pelas perspectivas dialógica, dialética, humanizante e libertadora.

Sem perder de vista esses pressupostos humanísticos, a educação vislumbrada alinha-se a uma proposta de projeto societário emancipatório no qual "a vida humana só tem sentido a partir da busca incessante da libertação de tudo aquilo que nos desumaniza e nos proíbe de ser mais humanos, dignos e livres em nosso ser existencialmente situado" (ZITKOSKI, 2005, p. 2).

No caso da educação em prisões na realidade brasileira, o panorama histórico explicita a real problemática em que se insere a educação em prisões, dada à fluidez e à baixa incidência das medidas governamentais implementadas até o final do século XX no Brasil.

Foi a partir da primeira década dos 2000 que se introduziram iniciativas importantes no tocante à definição de diretrizes a educação em prisões no país, especialmente no que se trata de marcos legais instituídos para esse fim. Notadamente no que se refere ao desenvolvimento da EJA em espaços de privação de liberdade, três marcos legais instituídos merecem destaque. Primeiro, a inserção da educação em prisões no Plano Nacional de Educação - PNE. Segundo, o Parecer no 4/2010/CNE-CEB, que culminou na Resolução no 2, de 19 de maio de 2010/CNE-CEB (que dispõem sobre as diretrizes nacionais para a oferta de educação para jovens e adultos em situação de privação de liberdade nos estabelecimentos penais brasileiros). Terceiro, o Decreto 7. 626, de 24 de novembro de 2011, que institui o Plano Estratégico de Educação no âmbito do Sistema Prisional - PEESP. Todos eles representam avanços no que se refere à garantia de direitos de cidadania e às conquistas sociais relativas a esse público.

É importante frisar que outras ações foram também implantadas nos últimos dez anos para o sistema penitenciário brasileiro, resultante de um conjunto de esforços provenientes de manifestações, de movimentos sociais e de decisões políticas envolvendo organizações governamentais e entidades da sociedade civil. Dentre elas, destaca-se a possibilidade legal de desenvolver o PROEJA FIC/FUNDAMENTAL em articulação com a educação em prisões, advinda dos dispositivos e das diretrizes do PEESP, mais precisamente o item IV, que estabelece vias de fortalecimento da integração da EPT com a EJA no sistema prisional.

Muito embora se estabeleçam, em tese, em incentivos importantes, no caso das atividades educacionais em prisões, constata-se que esses mecanismos legais não tem sido suficientes para a 
ampliação das ofertas. Com a preocupação central de refletir sobre a efetividade do praticado, apresenta-se, a seguir, as estatísticas do sistema penitenciário brasileiro. A tentativa é cotejar informações sobre o perfil das pessoas privadas de liberdade e contrastá-las com as ações vigentes para o desenvolvimento de atividades educacionais no interior dos presídios. O foco da discussão dos dados das tabelas que seguem são de caráter mais geral, centrados nos indicadores do perfil demonstrado.

Nessa direção, a Tabela 1, a seguir, mostra algumas estatísticas do Sistema Penitenciário Brasileiro relativas aos anos de 2010 a 2012.

Tabela 1 - Quantidade e perfil de pessoas privadas de liberdade do Sistema Penitenciário Brasileiro (2010 - 2012 )

\begin{tabular}{|c|c|c|c|c|c|c|c|c|c|c|c|c|c|c|}
\hline \multirow{2}{*}{ 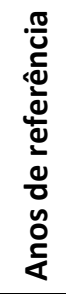 } & \multirow{2}{*}{ 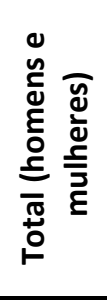 } & \multicolumn{8}{|c|}{ irau de instrução } & \multicolumn{5}{|c|}{$\begin{array}{c}\text { Envolvimento em atividades } \\
\text { educacionais }\end{array}$} \\
\hline & & $\begin{array}{l}0 \\
+0 \\
0 \\
0 \\
\frac{0}{0} \\
\frac{4}{0} \\
\frac{1}{4} \\
\end{array}$ & 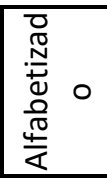 & 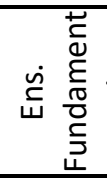 & 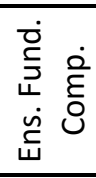 & 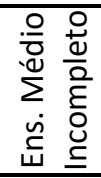 & 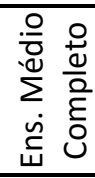 & 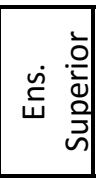 & 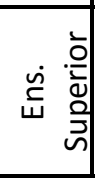 & 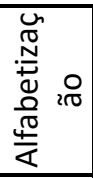 & 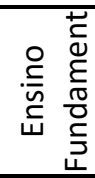 & 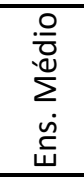 & 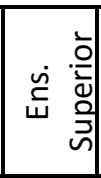 & 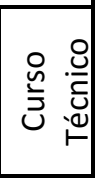 \\
\hline \multirow{2}{*}{2010} & \multirow{2}{*}{496.251} & 25.319 & 55.783 & 201.938 & 52.826 & 47.461 & 32.661 & 3.134 & 1.829 & 9.583 & 22.028 & 6.468 & 265 & 1.670 \\
\hline & & $5,10 \%$ & $11.24 \%$ & $40,63 \%$ & $10,65 \%$ & $9,56 \%$ & $6,58 \%$ & $0,63 \%$ & $0,37 \%$ & $1,93 \%$ & $4,44 \%$ & $1,30 \%$ & $0,05 \%$ & $0,34 \%$ \\
\hline \multirow{2}{*}{2011} & \multirow{2}{*}{514.582} & 26.410 & 58.380 & 0 & 5 & 52.843 & 36.289 & 3.757 & 06 & 10.032 & 37 & 4 & 93 & .724 \\
\hline & & $5,13 \%$ & $11,35 \%$ &, $10 \%$ & $7 \%$ & $10,27 \%$ & $7,05 \%$ & $0,73 \%$ & $0,37 \%$ & $1,95 \%$ & $53 \%$ & $1,51 \%$ & $0,02 \%$ & $0,34 \%$ \\
\hline \multirow{2}{*}{2012} & \multirow{2}{*}{548.003} & 27.813 & 64.102 & .429 & 62.175 & 56.770 & 38.788 & 4.083 & 2.050 & 8.392 & 29.117 & 7.289 & 178 & 2.377 \\
\hline & & $5,08 \%$ & $11,70 \%$ & $2,23 \%$ & $11,35 \%$ & $10,36 \%$ & $7,08 \%$ & $0,75 \%$ & $0,37 \%$ & $1,53 \%$ & $5,31 \%$ & $1,33 \%$ & $0,03 \%$ & $0,43 \%$ \\
\hline
\end{tabular}

Fonte: Formulário Categoria e Indicadores Preenchidos - Ministério da Justiça (2010-2012)

Em números absolutos, os quantitativos demonstrados na tabela 3 evidenciam, dentre outros elementos qualitativos, o perfil de escolarização das pessoas privadas de liberdade dos presídios brasileiros, com base nos relatórios divulgados pelo Ministério da Justiça (BRASIL, 2013) entre os anos de 2010 a 2012. Os dados revelados remetem-se ao conjunto de instâncias que compõem as prisões do país.

Constata-se, em relação ao grau de instrução, que a maioria das pessoas em situação de aprisionamento está entre analfabetas e com ensino fundamental completo. Tomando como exemplo o ano de 2012, dos 548.003 há concentração de 59,01\% entre analfabetos, apenas alfabetizados e com ensino fundamental incompleto. Considerando se tratar de pessoas com faixa etária de 18 anos ou mais (inclusive os acima dos 60 anos de idade), esse público configura uma demanda potencial de educação de jovens e adultos. Entretanto, as atividades educacionais desenvolvidas no interior das prisões deixam a desejar.

Nenhuma das ações formativas classificadas na Tabela 1 atende, a contento, o público a quem se destina. Em 2012, os percentuais mostram a seguinte relação: dos 323.344 que se declararam analfabetas, alfabetizadas e com ensino fundamental incompleto, apenas $6,84 \%$ estão envolvidas em atividades educativas dentro da prisão. Isso representa uma estatística questionável, a qual aponta para a ingestão do Estado brasileiro no que se refere a negação da educação como um direito humano de cidadania e pela ineficiência na formulação de políticas públicas destinadas a essa demanda real de formação. Com isso, muitas pessoas privadas de liberdade estão excluídas do processo educacional, seja ele formal ou não-formal, e de educação geral ou formação profissional e até dos dois juntos. 
No que tange aos dados prisionais locais, toma-se como referência para situar o estado do Rio Grande do Norte, também, o ano base de 2012, conforme informações da tabela 2 a seguir.

Tabela 2 - Quantidade e perfil de pessoas privadas de liberdade no estado do Rio Grande do Norte (2012)

\begin{tabular}{|c|c|c|c|c|c|c|c|c|c|c|c|c|c|c|}
\hline \multirow{2}{*}{ 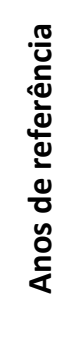 } & \multirow{2}{*}{ 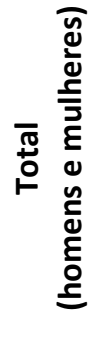 } & \multicolumn{8}{|c|}{ Grau de instrução } & \multicolumn{5}{|c|}{$\begin{array}{c}\text { Envolvimento em atividades } \\
\text { educacionais }\end{array}$} \\
\hline & & 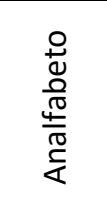 & $\begin{array}{l}\frac{0}{0} \\
\frac{0}{0} \\
\stackrel{N}{1} \\
\frac{0}{10} \\
\frac{0}{60} \\
\frac{\pi}{4}\end{array}$ & 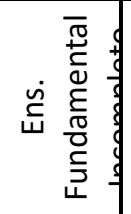 & 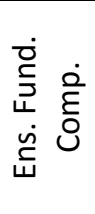 & 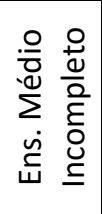 & 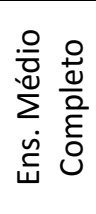 & 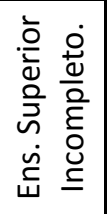 & 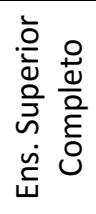 & 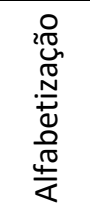 & 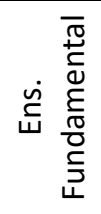 & 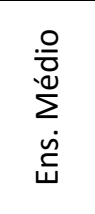 & 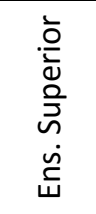 & 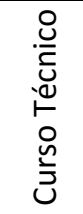 \\
\hline \multirow{2}{*}{2012} & \multirow{2}{*}{$5.845^{*}$} & 905 & 957 & 1625 & 459 & 250 & 151 & 44 & 27 & 66 & 37 & 19 & 0 & 15 \\
\hline & & $15,48 \%$ & $16,37 \%$ & $27,80 \%$ & $7,85 \%$ & $4,28 \%$ & $2,58 \%$ & $0,75 \%$ & $0,46 \%$ & $1,13 \%$ & $0,63 \%$ & $0,33 \%$ & $0,00 \%$ & $0,26 \%$ \\
\hline
\end{tabular}

* O relatório constata uma diferença no total de 1.182 detentos (não informados). Sendo assim, a população carcerária do RN em 2012 era de 7.141 detentos. Para efeitos desse relatório, foi considerado o total de detentos informados - 5.845.

Fonte: Formulário Categoria e Indicadores Preenchidos - Ministério da Justiça (2012).

Desse diagnóstico, constata-se que os indicadores que caracterizam o grau de instrução não diferem entre as duas esferas. Em relação ao nível de instrução, dos 5.845 privados de liberdade no estado que declararam o grau de instrução, 59,65\% estão entre analfabetos, alfabetizados e ensino fundamental incompleto. Por outro lado, os percentuais de envolvimento dessas pessoas com atividades educacionais nesses níveis na prisão no RN são emblemáticos: apenas 1,76\%. Isso demonstra a omissão do poder público, na esfera estadual, com a função social do instituído prisão.

Dos fatores apresentados nas tabelas 1 e 2, entrecruzando-os com os pontos de vista apresentados na seção anterior, percebe-se que figura, nos dois panoramas, uma demanda potencial para o desenvolvimento de ações educativas articuladas, envolvendo EJA, qualificação profissional - cursos FIC e educação em prisões. Logo, um espaço propício para desenvolver o PROEJA FIC/FUNDAMENTAL na forma prisional. É nesse patamar que se inscrevem tanto a defesa pela necessária articulação originada nas intenções e nas finalidades desse Programa como os desafios impostos, na prática, na união da EJA, da qualificação profissional-cursos FIC e da educação em prisões.

\subsection{IMPRESSÕES DOS SUJEITOS ACERCA DO CURSO INVESTIGADO}

De todos os aspectos que permeiam o processo de funcionamento do Curso, são objetos dessa problematização a gestão dos processos administrativos e pedagógicos e o Projeto Pedagógico de Curso.

Atendo-se aos itens nucleares desse estudo, define-se que a gestão dos processos pedagógicos é o centro de onde emanam as diretrizes, as decisões, as orientações, as definições e os encaminhamentos para o funcionamento da escola e, no caso em análise, para o funcionamento do curso. Desse modo, gestão administrativa e gestão pedagógica, conjuntamente, são atuações articuladas em prol da organicidade do processo educativo (DEMO, 1993). O que conduzirá a abordagem deste item, com base nas duas dimensões de análises pautadas, é o entendimento de gestão, em sentido amplo, que concebe processos administrativos e político-pedagógicos 
conjuntos e envolve os diversos segmentos existentes na participação, na organização e nas decisões, em que o cerne é o trabalho pedagógico.

Nesse particular, a forma de conduzir as atividades integradoras, o encaminhamento dos processos decisórios, a dinâmica do cotidiano da 'cela de aula', a definição das condições de funcionamento do curso, o direcionamento para o trabalho coletivo e conjunto, a organização das atividades pedagógicas, o uso dos recursos didáticos e a formação continuada em serviço, são os vieses observados na condução da gestão pedagógica e administrativa do IFRN-campus Mossoró, no sentido de verificar fatores que facilitaram e que dificultaram o funcionamento do referido Curso.

Um dos critérios importantes para ser observado é sobre como foi conduzida, pela gestão, a escolha do curso. Os dados revelaram, com clareza que a decisão pelo referido curso não teve a participação dos estudantes. Ocorre que, mesmo sem o direito de optar, dos seis entrevistados, cinco foram favoráveis ao curso oferecido, apontando que a escolha foi adequada. Apenas um deixou de responder.

Nota-se que esse fator pode ser atribuído à situação de privação de liberdade dos estudantes. No cotidiano do sistema prisional brasileiro, em vista das condições efetivas de cumprimento de pena dos internos que lhes faltam alternativas, sobretudo de atividades educacionais, o critério afinidade com a área/eixo não se constitui, para os estudantes, no elemento definidor para escolher um curso. Ademais, muitos dos internos dificilmente tiveram outra oportunidade igual em seu entorno social, por isso, o atributo preferência (ou não) pelo curso não prevaleceu. Portanto, estudar, elevar a escolaridade, poder fazer um curso de qualificação profissional - curso FIC associado à modalidade EJA como esse, no instituído 'prisão', parece significar condição suficiente para as pessoas que vivem em regime de privação de liberdade.

Dos argumentos apresentados, dois estudantes afirmaram que a escolha do curso foi acertada em razão de servir para a ampliação dos conhecimentos. Esse atributo confere à educação o título de vetor da aquisição dos saberes historicamente construídos. Esse segmento avalia o curso positivamente a partir do aprendizado adquirido por meio dele. Já para E2, a excelência da escolha do curso reside no fato de que "ele [o curso] é preparatório para que o preso consiga um emprego quando da sua liberdade". Esse ponto de vista é reincidente nestas análises, como discutido na seção anterior: a noção de educação profissional/curso profissionalizante como emprego certo (futuro ou imediato). Quando a qualificação profissional - cursos FIC é compreendida exclusivamente sob esse viés, pode-se desconsiderar a natureza da educação profissional que deve ser "determinada, fundamentalmente, por finalidades sociais e não por interesses individuais ou de mercado unicamente" (ARAÚJO, 2002, s/p).

Sobre o ponto de vista dos docentes e gestores acerca da escolha do curso, parece ter sido uma condição determinante, nessa definição, as efetivas condições de desenvolvimento do curso, considerando o espaço escolar não-formal ser uma prisão, dada a natureza da oferta de qualificação profissional - cursos FIC que exige, dentre outras atividades, a realização de aulas práticas e teóricas.

Os dados extraídos das falas de docentes e gestores mostraram que, ao contrário da constatação de que o grupo de estudantes não opinou, o processo de escolha que definiu o curso foi amplamente discutido e analisado entre esses dois segmentos. Esse fato confere que a definição pelo curso se deu no âmbito dos gestores e docentes, sob critérios de adequação de 
espaço físico e de estrutura de pessoal, com base nas condições de funcionamento no espaço prisional, conforme o posicionamento a seguir.

A ociosidade dos alunos, dos internos, o tempo disponível que eles tinham para leitura e as limitações que nós, os professores, teríamos para desenvolver o projeto lá, considerando que não se poderia trabalhar com aulas práticas, tinha de ser um curso quase que eminentemente teórico. Então, isso foi decisivo para a escolha desse curso, né, esses elementos foram decisivos (G4, 2013).

O fator 'adequação' na definição de um curso se faz necessário, sobretudo se for considerado a situação de restrição e de privação de liberdade em que se encontram os estudantes. A cuidada ponderação dos critérios da escolha interligados com o mundo do trabalho pode funcionar como um facilitador, em especial, em razão de o Curso aliar elevação de escolaridade à qualificação profissional-cursos FIC.

Ainda que se reconheça, nas falas de docentes e gestores, elementos imprescindíveis para se definir um curso, como visitas a locais onde o curso vai funcionar, levantamento das condições efetivas de desenvolvimento, reuniões para escuta da equipe de profissionais e parceiras envolvidas no curso, mesmo assim, a consulta aos futuros alunos do curso sobre suas preferências, um diagnóstico preliminar sobre as áreas de afinidades e o perfil educativo deles constituiriam mecanismos importantes nessa escolha. No entanto, a partir das falas dos três segmentos, isso não aconteceu. Mesmo assim, na percepção geral dos sujeitos, a escolha parece ter sido acertada. $\mathrm{E}$ isso pode ser constatado pelo nível de satisfação com o curso escolhido, demonstrado pelos estudantes.

As informações relatadas a seguir trazem as impressões dos estudantes em relação ao curso desenvolvido no formato do PROEJA FIC/FUNDAMENTAL.

É fundamental fazer um curso que une o ensino fundamental a uma qualificação profissional ao mesmo tempo, porque ao mesmo tempo estamos fazendo dois cursos em um só e excelente concluir o ensino fundamental e ao mesmo tempo se profissionalizar $(E 6,2013)$.

O curso foi muito proveitoso, abriu as janelas para quem estava há muito tempo sem estudar. Seria ideal outros cursos para continuar estudando $(E 2,2013)$.

O diploma deste curso é o cartão de visitas. Ao sair da prisão, chegar a uma empresa, mostrar o diploma é uma referência. O olhar sobre o ex-presidiário vai ser outro, pois vão dizer: apesar de estar preso, ele estava estudando (E1, 2013, informação verbal).

A visão dos estudantes enfatiza o diferencial de se concluir um curso que une o ensino fundamental a uma qualificação profissional ao mesmo tempo. É oportuno destacar que, nesses depoimentos, a representação dos sujeitos advindas de suas histórias de vida são determinantes. As referências explícitas de satisfação com o curso que E1 faz demonstram que essa formação trouxe implicações para a vida desse aluno, relacionado ao futuro, ao vir-a-ser dele, uma vez que está em situação de privação de liberdade. Em seu conjunto, os depoimentos focalizam as possibilidades de mudanças que a educação pode ocasionar na vida das pessoas jovens e adultas sem nenhuma ou com pouca escolaridade. Isso pode ser percebido na intervenção de E2 ao afirmar que "o curso abriu as janelas para quem estava há muito tempo sem estudar. Seria ideal outros 
cursos para continuar estudando". A expressão 'continuidade dos estudos', reitera, aqui, o conclamado direito à educação.

Em resposta ao questionamento feito se o curso contribuiu para alguma mudança na vida deles, os alunos responderam que sim. Dentre as justificativas mais expressivas para esse debate, temos: "por quê a [há] quase quatorze anos eu não estudava, agora estou com muita vontade de continuar os meus estudos, que me trouxe a alta estima de volta (E5, 2013)"; " Proporciona um aprendizado enorme e te oferece uma profissão lá fora. Tudo depende de você para a mudança de vida. A semente foi plantada" (E2, 2013); e "Eu já me considero transformado, esse curso foi importante para mim, não só para mim, como também para todos, eu creio, ele abriu nossa mente para o futuro" (E3, 2014).

Infere-se, dessas percepções, os alcances do referido Curso. Implica dizer que, além de qualificar profissionalmente para uma atuação no mundo do trabalho, o desenvolvimento do curso extrapolou os limites dos meios de produção e proporcionou mudanças de vida. "Muito mais que conteúdos, os professores nos ensinaram coisas importantes para a nossa vida, aprendemos muito com eles (E3, 2012, informação verbal). De fato, isso remete à amplitude dos propósitos e dos alcances da educação institucionalizada. Para as pessoas jovens, adultas e idosas que não conseguiram concluir seus estudos na denominada idade própria, voltar a estudar pode ser uma oportunidade para ressignificar a vida, para dar um novo estímulo de vida e até para elevar a autoestima, consoante demonstra E5. Esse pensamento induz afirmar que, em quaisquer fases e circunstâncias de vida em que se encontra um ser humano, a educação pode ser um mecanismo social eficaz capaz de entrever positivamente na formação do ser humano. E é sob o prisma do caráter transformador (FREIRE, 1999), que a educação deve ser assumida, sempre.

A justificativa abaixo, dada por um dos estudantes questionados se a conclusão do respectivo curso contribuiria para alguma mudança de vida, ilustra o apontado.

Sim. Porque nunca tinha feito nenhum curso profissionalizante, então eu não tinha como conseguir um emprego e hoje graças a Deus vou ter um diploma de um curso profissionalizante e quando eu sair da prisão vou poder apresentar um diploma para conseguir um trabalho honesto $(E 6,2013)$.

Esta é também um das marcas do discurso de um dos gestores. "Quando você junta as duas coisas, são duas necessidades que o indivíduo tem, que são necessárias, e que eu vou trabalhar junto. Não passa mais essa questão mais imediata, como essa outra questão da formação geral é muito importante $(G 1,2013)$.

É incontestável o teor neoliberal implícito na justificativa de E6 e, em parte, da fala de G1. Por outro lado, é perceptível a diferenciação feita ao comparar experiências anteriores que teve com outros tipos de formação com o PROEJA FIC/FUNDAMENTAL, assim como é inegável a representatividade da formação viabilizada por meio desse Programa para a história de vida desse estudante, haja vista a motivação revelada por fazer 'um curso profissionalizante'. O que está sendo vislumbrado por ele é o vir a ser. É a expectativa gerada por 'um trabalho honesto' no futuro. É nessa direção que se postula a Pedagogia da Esperança, uma vez que "não há utopia verdadeira fora da tensão entre a denúncia e o anúncio de um futuro a ser criado, construído, política, estética e eticamente, por nós, mulheres e homens" (FREIRE, 1999, p. 91). E, para quem está em cumprimento de pena por desvio de conduta, apontar para a possibilidade de conseguir um trabalho honesto, quiçá, configure ruptura de paradigma, mudança de comportamento. 
Esse posicionamento apresenta resquício da noção de empregabilidade incutida nos seres humanos pela lógica neoliberal como "uma falsa explicação que procura direcionar para os próprios indivíduos a responsabilidade pela sua condição de desempregado" (OLIVEIRA, 2008, p. 201). A empregabilidade tem sua gênese na desresponsabilização do Estado de cumprir com suas funções sociais básicas, entre elas, educação e emprego, e no fenômeno de desemprego em massa, em que a culpa pelo desemprego ou pela falta dele é atribuída à má qualificação profissional dos sujeitos socais.

A valorização do trabalho (como atividade laboral) em detrimento da educação na dinâmica dos presídios, além de não incentivar a adesão dos apenados pela escolarização, descaracteriza-a (a educação) como um direito, colocando-a na condição de opção e de benefício aos detentos, sob a ótica da remição de pena. Julião $(2011$, p. 217) analisa que "a valorização do trabalho frente à educação traz como consequência um maior estímulo à educação como mecanismo de acesso e preparo para o mercado de trabalho, em detrimento de outros objetivos do direito à educação como desenvolvimento pessoal ou formação para a cidadania". A tendência de que a educação funciona como um vetor de desenvolvimento, de garantia de emprego e de distribuição de renda justa e igualitária é ainda muito difundida. Igualmente controverso é incutir a ideia de que a educação é fator determinante de crescimento econômico, de aumento da produtividade ou de redução das desigualdades sociais, da pobreza e da miséria. Muito embora por meio dela se atinjam fins similares, a educação é, antes de tudo, um direito da pessoa humana (CIAVATTA, 2005).

Abordar a gestão dos processos administrativos e pedagógicos no funcionamento do curso implicou, primeiramente, na discussão sobre as dificuldades encontradas. "[...] A primeira dificuldade, e eu diria que a maior dificuldade, foi a constituição do quadro docente" (Gestor 4-G4, 2013, IFRN-MO). A constituição do quadro de docentes é uma ação que está prevista nas orientações oficiais para o desenvolvimento de cursos no âmbito do PROEJA FIC/FUNDAMENTAL em presídios brasileiros. E a problemática supramencionada por G4 está circunstanciada em dois polos: a composição de docentes para lecionar as disciplinas da qualificação profissional e de docentes para a educação básica - ensino fundamental EJA.

O primeiro caso reside na não adesão dos professores da área técnica do IFRN-MO, ou seja, não houve adesão ao Curso no âmbito do PROEJA FIC/FUNDAMENTAL por parte do quadro de docentes do IFRN. Esta situação, além de trazer implicações de ordem operacional para a gestão administrativa do curso, no sentido de compor a equipe de docentes, traduz-se em rejeição ao Programa. Atribui-se, talvez, ao fato de se tratar de um curso de qualificação profissional-curso FIC associado à EJA e, por isso, alguns docentes com experiência em outras formas de ofertas de EPT, teoricamente menos trabalhosas, resistam trabalhar com esse público.

O segundo caso situado diz respeito à não viabilidade de cessão de professores da rede estadual de ensino do RN para ministrar as disciplinas da formação geral - ensino fundamental/EJA no Curso, cessão essa prevista no Documento Orientador para o PROEJA FIC em prisões federais. A instituição parceira descumpriu com a contrapartida e não cedeu os docentes. O não cumprimento implicou no redimensionamento das ações planejadas, inclusive no tocante aos recursos financeiros, tendo em vista que a gestão administrativa do Curso investigado precisou mobilizar outros mecanismos para formar o grupo de profissionais que ministrariam as disciplinas da EJA, uma vez que a cessão de professores via SEEC/RN foi, em parte, destituída. 
O descumprimento dos compromissos assumidos foi preocupação reincidente no grupo de gestores e docentes do curso quando se refere à avaliação das relações estabelecidas entre as três instituições envolvidas na ação educativa. São elas: o IFRN-MO, a SEEC/RN e a Penitenciária Federal de Mossoró.

A referência ao descaso foi algo recorrente nas falas, o que incide na falta de uma política de incentivos aos profissionais que atuam na educação em prisões, dada à situação de periculosidade em que são submetidos. Os relatos que seguem levam a crer que, no estado do RN, esses mecanismos não têm funcionado a contento. As observações feitas são emblemáticas. É perceptível que os problemas da educação pública brasileira, em destaque os da modalidade EJA, da qualificação profissional-cursos FIC e da educação em prisões, independente da esfera administrativa que habita, do nível, da modalidade ou do espaço em que esteja inserida, guardam sintonia das problemáticas entre si.

Em face das dificuldades citadas acerca do quadro de pessoal e da falta de incentivos aos profissionais, convém enfatizar que o perfil e a remuneração dos profissionais para atuar na educação de pessoas jovens e adultas em situação de privação de liberdade estão referendados no artigo 11, § 1으, da Resolução no 2/2010, que trata das diretrizes para essa oferta ao determinar que "Os docentes que atuam nos espaços penais deverão ser profissionais do magistério habilitados e com remuneração condizentes com as especificidades da função" (BRASIL, 2010b, $s / p)$. Na visão dos entrevistados, em vista desses atributos não serem levados em consideração, gera-se certo desconforto que exige intervenção frequente na condução dos processos por parte do gestor.

Logo, diante dos pontos de vista externados nas falas, é premente que uma experiência como essa aponta para a necessidade de formação continuada. E dos incentivos dados, a formação continuada para os profissionais envolvidos no Curso foi um item avaliado positivamente pela a equipe. A fala a seguir corrobora com esse entendimento e demonstra, com detalhes, como essa ação aconteceu.

Nós tivemos um curso de formação durante um período bem... bem significativo, um curso de 200 horas que fez uma diferença significativa tanto quanto em vista do conhecimento quanto das posturas que precisavam ser abordadas lá. E, sobretudo, porque funcionou como espaço de alimentação e retroalimentação do grupo. [...] (G4, 2013, IFRN-MO).

O relato de G4 delineia o contorno dessa formação continuada, o que posiciona essa ação como uma potencialidade do PROEJA FIC/FUNDAMENTAL. O Programa prevê recursos para a formação de gestores, professores e técnicos-administrativos envolvidos no desenvolvimento dos cursos (BRASIL, 2007b, p. 51).

Os dados revelaram que, na visão dos docentes, a formação continuada proporcionou a unidade do grupo, contribuiu para um trabalho pedagógico coeso e interdisciplinar, favoreceu o bom desempenho docente e discente e o desenvolvimento das aulas, dentre outras vantagens. Em vista da representatividade dessa formação para esses profissionais, conforme declararam em suas falas, especialmente por ter acontecido em paralelo ao desenvolvimento do curso com os estudantes, de um modo geral, o projeto de formação continuada, promovido pela gestão do IFRNcampus Mossoró como uma das etapas operacionais necessárias ao funcionamento do Curso em análise, no âmbito do PROEJA FIC/ FUNDAMENTAL, atende à necessidade formativa dos 
profissionais e está na direção adequada, segundo planejamento feito a priori. E dando maior consistência '[...] No caso do PROEJA FIC aqui, essa nossa experiência, ela está junto com o curso de formação, então uma coisa que deu certo é a existência desse curso de formação para trabalhar com esse público específico (D3, 2013).

Ainda na perspectiva das potencialidades e das fragilidades, outros fatores relevantes no funcionamento do curso são a operacionalização dos recursos didáticos, a adequação da infraestrutura e a organização dos tempos, dos espaços e das atividades pedagógicas.

Nesse ordenamento, a logística necessária para o funcionamento do curso, no tocante à aplicação dos recursos financeiros e ao cotidiano das aulas, mobiliza gestores (de ambas as instituições), professores e estudantes, o que pressupõe antecipação do planejamento, negociação, fiscalização, inspeção, compromisso e flexibilidade por parte da equipe.

A síntese descrita pelas falas demonstraram que a condução desses processos não é simples. Demanda cooperação, sobretudo dos funcionários da prisão, na acolhida dos docentes e na acomodação dos estudantes para que o processo ensino e aprendizagem ocorra a contento dentro daquelas condições reais de efetivação. Os desafios cotidianos nessa condução são perceptíveis nas falas dos sujeitos investigados. Portanto, ficam notórios o processo de negociação instaurado e os esforços conjuntos empreendidos na dinâmica das aulas. Como complemento da avaliação das condições de funcionamento do curso, na visão dos estudantes, entre os facilitadores do desenvolvimento do curso, na sua maioria, remeteram-se a atuação dos docentes e ao tempo disponível que eles têm para estudar, considerando a situação de privação de liberdade em que eles se encontram. No geral, esses atributos são favoráveis à gestão dos processos pedagógicos para o desenvolvimento do curso.

Entre os itens elencados como dificultadores, a maioria (caneta, revista e grade) remete-se às condições estruturais e de materiais didáticos de uso dos estudantes para realizarem as tarefas. Isso ocorre em razão das restrições estabelecidas oficialmente, o que exige, na maioria das vezes, controle, improvisos e adaptações. Essa adequação, apesar de necessária, pode comprometer a realização das atividades ou exige redimensionamentos por parte do professor com frequência.

Muito embora se reconheça a existência de elementos dificultadores na gestão dos processos administrativos e pedagógicos, a exemplo dos que foram situados até o momento, dados apontam que funcionamento do Curso foi considerado satisfatório. Ao contrário dos pontos negativos, os pontos positivos do funcionamento do curso na visão dos estudantes estão centrados, na grande maioria, em argumentos que potencializam os docentes do Curso. Há, no geral, um reconhecimento pela atuação dos docentes. Para eles, os docentes estão bem preparados para o desempenho de do papel dentro da sala de aula. Esse fator pode ter sido o diferencial que contribuiu para a permanência e a conclusão dos estudos com sucesso.

Apesar das dificuldades em gerir processos administrativos e pedagógicos para o funcionamento do curso por parte de toda a equipe e de alguns entraves constatados na adaptação à dinâmica do espaço escolar não formal-prisão por parte dos estudantes, é visível a satisfação de todos os segmentos com a proposta de promover a integração entre a modalidade EJA e a educação profissional-cursos FIC. Os docentes do curso, em parte, sem experiência com a docência, em especial com o público EJA, vivenciaram emoções, reações, ansiedades, expectativas, frustrações, satisfações e realizações. 
O debate, no decorrer dessa tópico, abordou a gestão dos processos pedagógicos e administrativos que permearam o funcionamento do Curso em meio à integração anunciada entre EJA, qualificação Profissional - cursos FIC e o universo conflituoso da educação para pessoas jovens e adultas em situação de privação de liberdade.

Apesar da síntese descrita nesta seção não conseguir expressar, com a devida propriedade, as razões, os conflitos, as contradições, as tensões, as riquezas, as contribuições, as negações, as afirmações e os alcances tangíveis e intangíveis da experiência investigada, é incontestável a valorosa singularidade das percepções e impressões dos sujeitos, retroalimentadas pela análise documental e o diálogo mantido com os teóricos da área. Estes entrecruzamentos possibilitaram refletir sobre as intenções declaradas no Programa e sobre as ações gestadas para o funcionamento do Curso em questão, com o intuito de favorecer, dentre outros motivos, conjeturas de naturezas científica, política e acadêmico-pedagógica prováveis à avaliação e à reflexão das bases, dos fundamentos, das declarações oficiais, da abrangência do PROEJA FIC/FUNDAMENTAL e do e do aprimoramento do curso desenvolvido em articulação com a educação em prisões.

\section{CONSIDERAÇÕES SEMPRE PROVISÓRIAS}

Na direção de refletir sobre as sempre provisórias constatações conclusivas, apresentamse duas declarações fundamentais incididas nesse debate.

Em primeiro lugar, reconhece-se a relevância social das intenções do PROEJA FIC/FUNDAMENTAL como uma medida governamental que anuncia ser parte de uma política social inclusiva e emancipatória. Entretanto, infere-se que há muito mais correspondência das intenções declaradas com os anseios da população destinatária da educação para pessoas jovens, adultas e idosas como direito ao longo da vida, como prioridade social e como política pública de Estado do que com os reais alcances do Programa em nível nacional e local. No cerne dessa primeira declaração residem aspectos relevantes ao debate, como a exclusão social, a democratização do ensino e a universalização da educação como direito humano inalienável, em especial no Brasil, uma vez que o discurso do acesso de todos à educação para a vida toda, com garantia da permanência e da conclusão dos estudos com qualidade e com sucesso, é ainda mais patente.

Em segundo lugar, em face dos pressupostos da associação do PROEJA FIC/ FUDAMENTAL com o universo da educação em prisões no Brasil, a confluência em que habita o Programa inspira preocupação e atenção, pois exige decisão política por parte dos gestores públicos em prol da efetividade da ação e assunção pelos compromissos assumidos por parte dos órgãos responsáveis e parceiros envolvidos nesse desenvolvimento. Essa segunda declaração é incisiva e remete à necessária vontade política para fazer valer os dispositivos previstos na legislação educacional para a EJA, no geral, e no sistema prisional, especificamente, e à assunção dos compromissos por parte dos órgãos responsáveis e parceiros envolvidos no desenvolvimento do Programa na esfera prisional brasileira.

É lícito supor que o PROEJA FIC/FUNDAMENTAL agrega dois direitos do cidadão: o direito ao saber, à educação e o direito à humanização. Implica reconhecer que, historicamente, esses direitos foram negados. Por isso, não basta, apenas, fazer o Programa funcionar. É preciso assegurar, aos estudantes e demais envolvidos em cursos no âmbito desse programa, o direito à 
humanização. É na vertente da humanização que se persegue o alcance dos propósitos e das intenções declaradas oficialmente na formulação de suas bases e de seus fundamentos.

Tendo como parâmetro o Curso FIC de Auxiliar Técnico em Gestão e Qualidade em Serviços, na forma integrada ao ensino fundamental, na modalidade EJA, no âmbito do PROEJA FIC/FUNDAMENTAL, desenvolvido pelo IFRN-MO em espaço prisional, compreendendo o período de 2011 a 2013, a partir a partir das análises feitas das impressões e percepções dos sujeitos, conclui-se que a educação pode, sim, colaborar com o projeto de ressocialização das pessoas em situação de restrição e de privação de liberdade. E quando o projeto formativo proposto visa a elevação da escolaridade por meio da modalidade EJA, associada a uma qualificação profissionalcursos FIC, assim como o idealizado na integração anunciada no PROEJA FIC/FUNDAMENTAL, embora haja restrições em razão das condições de viabilização do funcionamento de um curso no espaço escolar não-formal 'prisão', esse modelo torna-se mais significativo e promissor para esses sujeitos.

Contudo, há que se pensar nos condicionantes sinalizados pela ausência de ações educativas no cenário nacional e local do sistema prisional brasileiro. Há que se refletir, ainda, sobre a necessária aproximação entre educação e prisão, notadamente no que se refere às interfaces relacionais esboçadas entre EJA, qualificação profissional-cursos FIC e trabalho como princípio educativo. Há que se pensar, primordialmente no Brasil e no Rio Grande do Norte, sobre o direito universal à educação ao longo da vida para todo e qualquer ser social em quaisquer que sejam as circunstâncias de vida desses sujeitos. O que não se pode é que prescindir de projetos educativos de cunho integrador e humanizador cujo parâmetro seja a ressocialização de pessoas jovens, adultas e idosas em situação de restrição e de privação de liberdade.

\section{REFERÊNCIAS BIBLIOGRÁFICAS}

1. ARAÚJO, R. M. de L. A reforma da educação profissional sob a ótica da noção de competências. Trabalho apresentado na 25a Reunião Anual da ANPED- 2002. Disponível em: <http://www.senac.br/BTS/283/boltec283a.htm >. Acesso em: 30 nov. 2013.

2. BRASIL. Parecer CNE/CEB no 4-2010. Diretrizes Nacionais para a oferta de educação para jovens e adultos em situação de privação de liberdade nos estabelecimentos penais. Relator: Adeum Hilários Sauer. Aprovado em 9 de março de 2010.

3. Decreto no 5.478, de 24 de junho de 2005. Institui, no âmbito das instituições federais de educação tecnológica, o Programa de Integração da Educação Profissional ao Ensino Médio na Modalidade de Educação de Jovens e Adultos - PROEJA. Brasília: 2005.

4.

Decreto no 7.626, de 24 de novembro de 2011. Institui o Plano Estratégico da Educação no âmbito do Sistema Prisional. Brasília: 2011b.

5. __ Lei $\mathbf{n}^{\circ}$ 9.394, de 20 de dezembro de 1996. Lei de diretrizes e bases da educação nacional. Diário Oficial [da] República Federativa do Brasil, Poder Executivo, Brasília, DF, v. 134, n. 248, 23 dez. 1996. Disponível em: <http://www.planalto.gov.br/ccivil/LEIS/L9394.htm>. Acesso em: 05 mai. 2012.

6. _. Ministério da Educação. Resolução no 2, de 19 de maio de 2010. Dispõe sobre as Diretrizes Nacionais para a oferta de educação para jovens e adultos em situação de privação de liberdade nos estabelecimentos penais. Brasília: MEC, 2010. 
7.

Ministério da Educação. Portaria MEC no 376, de 02 de fevereiro de 2005. Publicada no DOU em 03/02/2005. Disponível em: < http://www.fnde.gov.br/fnde/legislacao/portarias/ item/3533-portaria-mec-n\%C2\%BA-376-de-02-de-fevereiro-de-2005-publicada-no-dou-em03-02-2005> Acesso em 10 jul. de 2012

8. . Ministério da Educação. Secretaria da Educação Profissional e Tecnológica. Decreto no. 5.840, de julho de 2006. Institui, no âmbito federal, o programa Nacional de Integração da Educação Profissional com a Educação Básica na Modalidade de Educação de Jovens e Adultos - PROEJA. Brasília, DF, 2006.

9. Ministério da Educação. Secretaria da Educação Profissional e Tecnológica. Programa Nacional de Integração da Educação Profissional coma Educação Básica na Modalidade de Educação de Jovens e Adultos/Ensino Médio. Documento Base. MEC/SETEC: Brasília, 2007a.

10. Ministério da Educação. Secretaria da Educação Profissional e Tecnológica. Programa Nacional de Integração da Educação Profissional com a Educação Básica na Modalidade de Educação de Jovens e Adultos - Formação Inicial e continuada/ Ensino Fundamental - PROEJA FIC/FUNDAMENTAL. Documento Base. MEC/SETEC: Brasília, 2007b.

11. SETEC/MEC. Ofício Circular no 115/2010 - DPEPT/SETEC/MEC. Documento Orientador para PROEJAFIC em Prisões Federais. Brasília, 24 de agosto de 2010.

12. INSTITUTO BRASILEIRO DE GEOgRAFIA E ESTATístICA. Pesquisa Nacional por Amostra de Domicílios - PNAD 2007. Rio de Janeiro: IBGE, 2007.

13. Ministério Da Justiça. Departamento Penitenciário Nacional. Formulário Categoria e Indicadores Preenchidos Todas UF's . Sistema Integrado de Informações Penitenciárias InfoPen: Referência: 12 de 2010. Disponível em: http://portal.mj.gov.br/main.asp?View=\%7 B887A 0EF2-F514-4852-8FA9-D728D1CFC6A1\%7D\&Team=\&params=itemID=\%7BC 7442D559BC0-490C-8102-6522E6DD5EFC\%7D;\&UIPartUID=\%7B2868BA3C-1C72-4347-BE11A26F70F4CB26\%7D. Acesso em 14 nov. 2013.

14. BUENO, J. G. S. Apresentação. In: ONOFRE, Elenice Maria Cammarosano. (Org.). Educação escolar entre as grades. São Carlos: EDUFSCar, 2007.

15. CIAVATTA, M. O trabalho como princípio educativo: uma investigação teórico-metodológica (1930-1960). Rio de Janeiro: PUC-RJ, (Tese de Doutorado em Educação), 1990.

16.

A formação integrada: a escola e o trabalho como lugares de memória e de identidade. In: In: FRIGOTTO, Gaudêncio; CIAVATTA, M.; RAMOS, M. (Org.). Ensino médio integrado: concepção e contradições. São Paulo: Cortez, 2005.

17. FRIGOTTO, G.; CIAVATTA, M.; RAMOS, M. (Org.). Ensino médio integrado: concepção e contradições. São Paulo: Cortez, 2005.

18. DEMO, P. Desafios modernos da Educação. Petrópolis, RJ: Vozes, 1993.

19. FREIRE, P. Pedagogia da Esperança. São Paulo: Paz e Terra, 1994.

20. Educação e Mudança. Rio de Janeiro: Paz e terra, 1999.

21. Pedagogia do Oprimido.17 ed. Rio de Janeiro: Paz e Terra, 2005.

22. FOUCAULT, Michel. Vigiar e punir: nascimento da prisão. Tradução de R. Ramalhete. 29. Ed. Petrópolis: Vozes, 2001.

23. HADDAD, S.; DI PIERRO, M.C. Escolarização de Jovens e Adultos. Revista Brasileira de 
Educação. São Paulo, n.14, p. 108-130, maio/ago. 2000. p. 108-130.

24. JULIÃO, E. F. Educação e trabalho como programas de "reinserção social". In: LOURENÇO, A. da S.; ONOFRE, E. M. C. (Orgs.). O espaço da prisão e suas práticas educativas: enfoques e perspectivas contemporâneas. São Carlos: EDUFSCar, 2011.

25. MACHADO, M. M.; OLIVEIRA, J. F. de. A formação integrada do trabalhador: desafios de um campo em construção. São Paulo: Xamã, 2010.

26. MARX, K. Manuscritos econômicos-filosóficos. Lisboa: Edições 70. 1982.

27. MINAYO, M. C. de S. (Org). O desafio do conhecimento: pesquisa qualitativa em saúde. 12 ed. São Pulo: Editora Hucitec, 2010.

28. OLIVEIRA, R. de. Empregabilidade. In: PEREIRA, I. B.; LIMA, J. C. F. Dicionário da educação profissional em saúde. 2.ed. Rio de Janeiro: EPSJV, 2008.

29. ONOFRE, E. M. C. Escola da prisão: espaço de construção da identidade do homem aprisionado? In: . (Org.). Educação escolar entre as grades. São Carlos: EDUFSCar, 2007.

30. __ Educação escolar na prisão: controvérsias e caminhos de enfrentamento e superação da cilada. In: LOURENÇO, A. da S.; ONOFRE, E. M. C. (Orgs.). O espaço da prisão e suas práticas educativas: enfoques e perspectivas contemporâneas. São Carlos: EDUFSCar, 2011.

31. RAMOS, M. Trabalho, educação e correntes pedagógicas no Brasil: um estudo a partir da formação dos trabalhadores técnicos da saúde. Rio de Janeiro: EPSJV/Fiocruz; UFRJ, 2010.

32. _. Concepção de ensino médio integrado. Texto publicado em Seminário. Secretaria de Educação do Estado do Pará, 2007. Disponível em: <http://www.iiep.org.br/curriculo_ integrado.pdf>. Acesso em 10 jan. 2012.

33. ROCHA, J.M. Formação inicial de trabalhadores e elevação de escolaridade: políticas públicas de qualificação profissional em discussão (1963-2011). 2011. 276 f. Tese (Doutorado em Educação). Faculdade de Educação, Universidade de São Paulo, São Paulo, 2011.

34. PENNA, M. G. de O. Relações sociais e espaço escolar na prisão: limites e possibilidades da ação educativa no interior de uma penitenciária In: LOURENÇO, A. da S.; ONOFRE, E. M. C. (Orgs.). O espaço da prisão e suas práticas educativas: enfoques e perspectivas contemporâneas. São Carlos: EDUFSCar, 2011.

35. SCARFÓ, F.; BREGLIA, F.; FREJTMAN, Valéria. Sociedade Civil e educação pública nos presídios: questões para reflexão. In: LOURENÇO, A. da S.; ONOFRE, E. M. C. (Orgs.). O espaço da prisão e suas práticas educativas: enfoques e perspectivas contemporâneas. São Carlos: EDUFSCar, 2011.

36. TIRIBA, L.; CIAVATTA, M. (org.). Trabalho e educação de jovens e adultos. Brasília: Liber Livro e Editora UFF, 2011.

37. ZITKOSKI, J. J. O diálogo em Freire: caminho para a humanização. Revista Eletrônica Fórum Paulo Freire. Unisinos: 2005, ano 1, no 1, Julho. 